\title{
PENERAPAN SISTEM PENGECEKAN MAHASISWA LAYAK KKP BERBASIS YII FRAMEWORK PADA PERGURUAN TINGGI
}

\author{
Untung Rahardja'), Qurotul Aini ${ }^{2)}$, Vivid Kristiani Alfad Zebua ${ }^{3)}$ \\ ${ }^{123}$ Sistem Informasi STMIK Raharja \\ ${ }^{123} \mathrm{Jl}$. Jend. Sudirman No. 40, Modern Cikokol, Tangerang \\ Email : 'untung@raharja.info,2aini@raharja.info, ${ }^{3}$ vivid@raharja.info
}

\begin{abstract}
Abstrak
Pada zaman modern perkembangan teknologi sudah semakin pesat dan mudah diakses. Sebagai pelopor dalam bidang teknologi informasi, Perguruan Tinggi Raharja selalu berinovasi dalam hal penerapan teknologi. Karena teknologi memberikan kecepatan dan kemudahan kepada penggunanya. Namun saat ini pengecekan mahasiswa layak Kuliah Kerja Praktek (KKP) yang dilakukan oleh kepala jurusan masih belum memberikan kemudahan dan menjadi kurang efektif. Karena yang berjalan saat ini mahasiswa baru mengetahui bahwa dirinya layak KKP saat batal tambah OJRS + pada Sis PLus. Dalam penelitian ini terdapat 3 (tiga) permasalahan yang teridentifikasi mengenai pengecekan mahasiswa layak KKP pada Perguruan Tinggi Raharja yaitu sistem yang masih manual yang tidak terupdate dengan sendirinya, kurang optima, dan sistem yang masih bersifat lokal. Untuk memecahkan masalah dilakukan dengan metode analisa sistem dengan menggunakan metode UML (Unified Modeling Language) dan perancangan menggunakan yii framework. Alternatif pemecahan masalahnya adalah Viewboard Kepala Jurusan (VIKA), sebuah sistem pengecekan mahasiswa layak KKP online sehingga memudahkan kepala jurusan dalam pengecekan serta sistem yang sudah terintegrasi dan tidak perlu selalu di update yang dirancang dengan menggunakan yii adalah framework pemrograman umum web yang bisa dipakai untuk mengembangkan semua jenis aplikasi web. Diharapkan dengan adanya penelitian ini dapat memudahkan proses pengecekan mahasiswa layak KKP dan mampu meningkatkan mutu kegiatan perkuliahan pada Perguruan Tinggi Raharja.
\end{abstract}

Kata Kunci: Pengecekan, OJRS+, KKP, VIKA, Yii Framework.

\section{Pendahuluan}

Seiring dengan berjalannya waktu teknologi berkembang sangat cepat dengan memberikan pengaruh dan efek yang begitu besar di segala bidang kehidupan. Setiap saat terus bermunculan inovasi-inovasi teknologi yang begitu masif. Kondisi ini mengakibatkan perlunya penyesuaian terhadap gempuran arus digital agar dapat menyikapi kemajuan zaman. Selalu terbuka dengan teknologi baru adalah cara yang bijak agar dapat beradaptasi dengan baik oleh kemajuan teknologi, agar tidak terlalu tertinggal oleh gelombang modernisasi.

Sistem informasi sangat dibutuhkan guna pelayanan akademik yang lebih baik. Perguruan Tinggi Raharja sebagai penyelenggara pendidikan tinggi dibidang teknologi semakin berupaya meningkatkan mutu pendidikan dan pelayanan kepada mahasiswa dengan inovasi sistem informasi yang semakin berkembang. Ada banyak sistem informasi yang sangat berguna untuk menunjang kegiatan belajar yang ada dalam Perguruan Tinggi Raharja.

Salah satunya adalah sistem yang berguna untuk mengecek mahasiswa layak KKP (Kuliah Kerja Praktek). KKP atau Kuliah Kerja Praktek merupakan kegiatan berupa magang atau observasi oleh mahasiswa pada perusahaan atau instansi pemerintah secara terbimbing dan terpadu sebagai syarat kelulusan pada Perguruan Tinggi Raharja. Kegiatan ini dimaksudkan agar mahasiswa terlatih untuk dapat menerapkan pengetahuannya yang telah didapatkan selama perkuliahan. [1]

Menurut Neni Purwati dan Hendra Kurniawan (2015: 50) yang mengutip dari KBBI menyatakan bahwa pengecekan adalah suatu proses, cara, perbuatan mengecek, perbuatan melakukan pemeriksaan atau mencocokkan kembali kebenaran tentang suatu hal tertentu. [2] Mahasiswa dicocokkan dengan kriteria tertentu sesuai dengan syarat KKP jika ingin dinyatakan layak KKP. Syarat layak KKP ada tiga yaitu, lulus mata kuliah yang dipersyaratkan sesuai jurusan masingmasing, minimal 100 sks bagi strata 1 dan 70 sks bagi diploma 3 dan minimal IPK (Indeks Penilaian Kumulatif) 2.1. Dan harus menyelesaikan mata kuliah prasyarat IT Research dan Analisa Sistem Informasi untuk jenjang Diploma dan Sarjana. [3] Jika dari kriteria tersebut sudah dimiliki, maka mahasiswa tersebut dinyatakan layak untuk KKP dan akan diusulkan nama pembimbing untuk mahasiswa tersebut oleh Kajur (Kepala Jurusan).

Namun saat ini, sistem yang ada masih manual yaitu Kajur memilih nama pembimbing dan admin akan merekap data untuk diserahkan kepada akademik dan diteruskan ke OJRS+ untuk ditampilkan saat batal tambah. OJRS + digunakan sebagai sarana untuk melakukan batal tambah jadwal kuliah yang dapat diakses melalui SiS+ (Students iLearning Services Plus) secara online kapan pun dan dimanapun mahasiswa berada hanya dengan menggunakan koneksi internet. [4] 
Selain itu sistem tidak terupdate dengan sendirinya, artinya harus selalu di update secara berkala untuk memasukkan nama mahasiswa yang layak KKP. Kemudian, mahasiswa akan mengetahui bahwa ia telah layak KKP pada saat mahasiswa tersebut batal tambah pada OJRS+, akan muncul bahwa mahasiswa telah layak KKP beserta nama pembimbingnya yang telah dipilih oleh Kajur lewat sistem. Ini merupakan hal yang kurang efisien karena seharusnya sebuah sistem dapat meringankan kerja dari manusia, bukan malah menambah kerja manusia.

Untuk dapat memvalidasi KKP, mahasiswa harus login menggunakan Pribadi Raharja Card (PRC) dengan cara menggesekkan Pribadi Raharja Card (PRC) pada swipe card Box SIS (Student Information Services) untuk mencetak form validasi KKP, lalu mahasiswa harus menyerahkan form validasi KKP, kepada kajurnya masing-masing. Setelah itu, kajur akan mengecek berkasberkas dari mahasiswa tersebut untuk memberikan hasil verifikasi validasi layak atau tidak layak mahasiswa tersebut untuk KKP. [5]

Oleh karena itu diperlukan sebuah sistem yang dapat memberikan kemudahan bagi Kajur untuk menambah pembimbing dan dapat diakses secara online sehingga bisa diakses oleh Kajur. Pada sistem ini akan ada Viewboard yang memunculkan nama mahasiswa layak KKP secara otomatis. Sehingga tidak perlu lagi data didalam sistem untuk selalu di update. Sistem juga akan mampu diakses secara online, tidak mengharuskan Kajur untuk datang ke kampus hanya untuk mengakses sistem. Kajur dapat mengakses sistem dimana saja dan kapan saja. Dengan begitu sistem dapat bermanfaat bagi Kajur untuk meningkatkan kemudahan pengecekkan dan menambah pembimbing mahasiswa layak KKP.

Dengan permasalahan tersebut hadirlah sebuah inovasi baru yaitu sebuah sistem VIKA (Viewboard Kepala Jurusan) yang dirancang dengan menggunakan Yii adalah framework pemrograman umum Web yang bisa dipakai untuk mengembangkan semua jenis aplikasi Web. Yii memiliki komponen guna pengecekan input yang terintegrasi, ini merupakan fitur yang sangat penting untuk keamanan. [6] Dikarenakan sangat ringan dan dilengkapi dengan mekanisme caching yang canggih, Yii sangat cocok untuk pengembangan aplikasi dengan lalu lintas-tinggi, seperti portal, forum, sistem manajemen konten (CMS), sistem e-commerce, dan lainlain.

Sistem VIKA (Viewboard Kepala Jurusan) menjadi alat bantu bagi Kajur dalam pengecekkan mahasiswa layak KKP yang menjadi tanggung jawab Kajur. VIKA (Viewboard Kepala Jurusan) adalah sistem yang berisi viewboard memungkinkan kepala jurusan mendapatkan informasi tentang mahasiswa dan mengecek mahasiswa yang layak KKP. Dengan sistem ini, maka semakin mudahnya akses dan cara untuk menambah pembimbing serta sistem yang terintegrasi dengan baik dengan sistem lainnya yang sudah ada pada Perguruan Tinggi Raharja.

\section{Metode}

Model penerapan pada sistem ini menggunakan metode UML (Unified Modeling Language) sebagai sebuah "bahasa" yang standar bagi industri untuk memberikan gambaran, merancang dan mendokumentasikan sistem piranti lunak. UML menetapkan sebuah patokan guna merancang model sebuah sistem. [7] Penggunaan UML digunakan untuk menerangkan program dan alur yang berjalan.

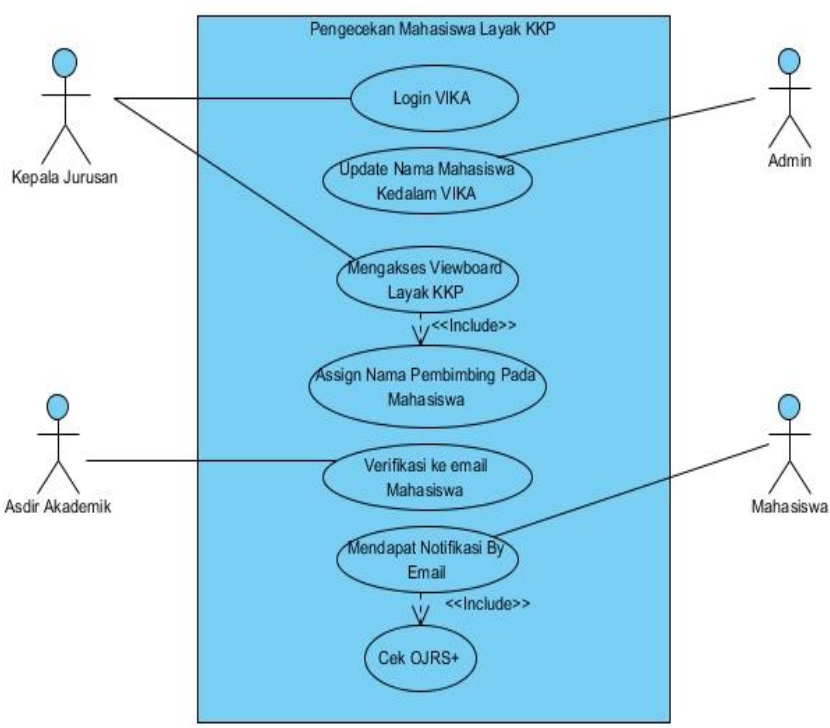

Gambar 1. Use Case Alur VIKA

Berikut ini adalah sebuah penjelasan tentang alur VIKA yaitu :

1. Kepala Jurusan login kedalam aplikasi VIKA

2. Admin mengupdate nama Mahasiswa kedalam VIKA

3. Kepala Jurusan mengakses Viewboard layak KKP

4. Kepala Jurusan assign nama pembimbing pada Mahasiswa

5. Asisten Direktur Akademik memberikan verifikasi assign pembimbing

6. Mahasiswa mendapat notifikasi layak KKP by email

7. Mahasiswa mengecek ke OJRS+ pada Sis Plus.

\section{Kode Program}

Pada halaman ini menampilkan konfigurasi kode program pada Yii Framework yaitu proses untuk memfilter nama mahasiswa yang layak KKP. 


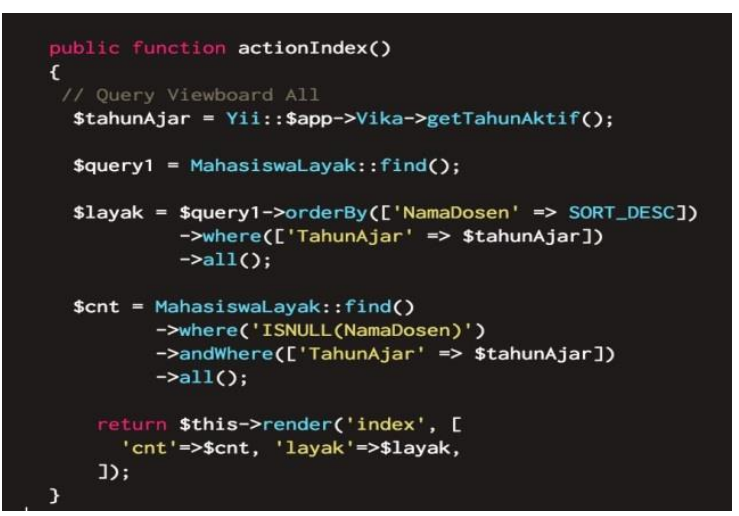

Gambar 2. Konfigurasi pada VIKA untuk menampilkan Mahasiswa layak KKP

\section{Hasil dan Pembahasan}

Pada bagian ini sistem VIKA sudah diimplementasikan di Perguruan Tinggi Raharja dalam mendukung pelaksanaan Kuliah Kerja Praktek. Namun untuk nilai jurnal yang akan di kunci pada sistem tersebut sedang dalam tahap uji coba dan akan segera diimplementasikan dalam sistem VIKA. VIKA (Viewboard Kepala Jurusan) adalah sebuah sistem yang digunakan oleh kepala jurusan untuk mengecek mahasiswa layak Kuliah Kerja Praktek (KKP). Pada sistem tersebut memungkinkan kepala jurusan untuk mengecek dan menambahkan pembimbing bagi mahasiswa layak KKP. VIKA dirancang untuk memudahkan pengecekan mahasiswa, dapat digunakan dimana saja dan kapan saja karena bersifat online.. Berikut akan dijabarkan beberapa hasil dari uji coba dan implementasi sistem VIKA berdasarkan data factual yang ada pada database sistem VIKA.

\section{Implementasi Halaman Utama dan Login VIKA}

Pada perancangan ini terdapat halaman utama VIKA dan langsung login menggunakan email Rinfo, tanpa perlu memasukkan username atau password. Email Rinfo ini dimiliki oleh Dosen yang sudah terdaftar sebagai Dosen Perguruan Tinggi Raharja.

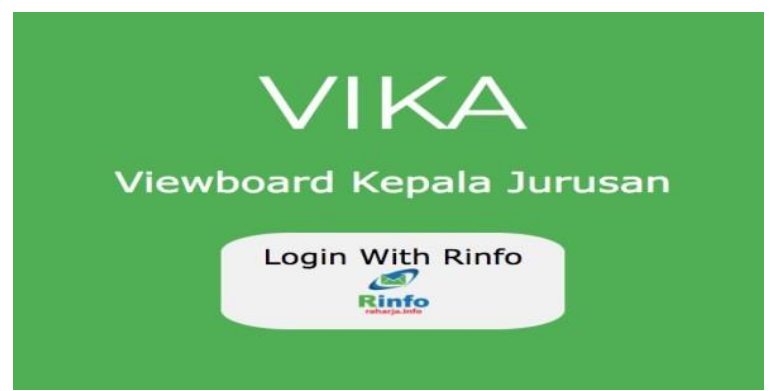

Gambar 3. Halaman Utama dan login pada VIKA

\section{Implementasi Tampilan Home Website}

Pada tampilan user setelah login, dalam hal ini website yang digunakan untuk media daftar mahasiswa layak KKP dan selanjutnya user akan assign nama dosen pembimbing.

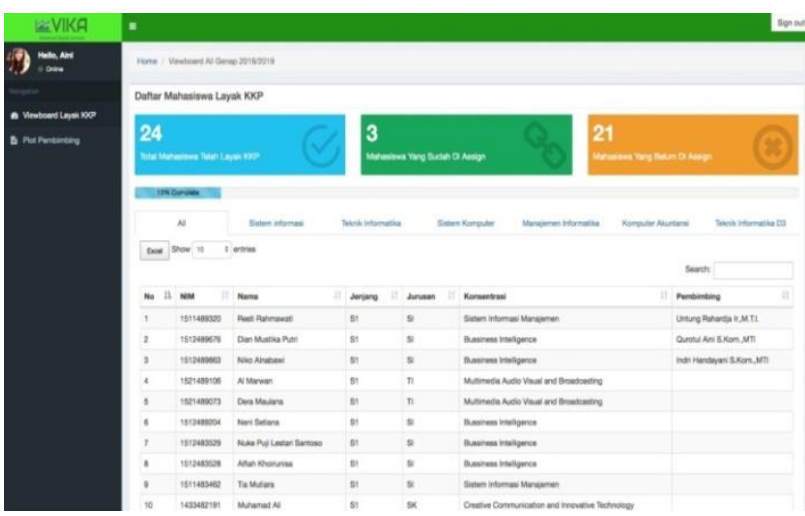

Gambar 4. Tampilan setelah login pada website yii framework

\section{Implementasi Tampilan Plot Pembimbing}

Pada menu ini daftar plotting dengan nama dosen pembimbing, yang kemudian user akan memasukkan jumlah mahasiswa yang akan dibimbing oleh dosen pembimbing tersebut.

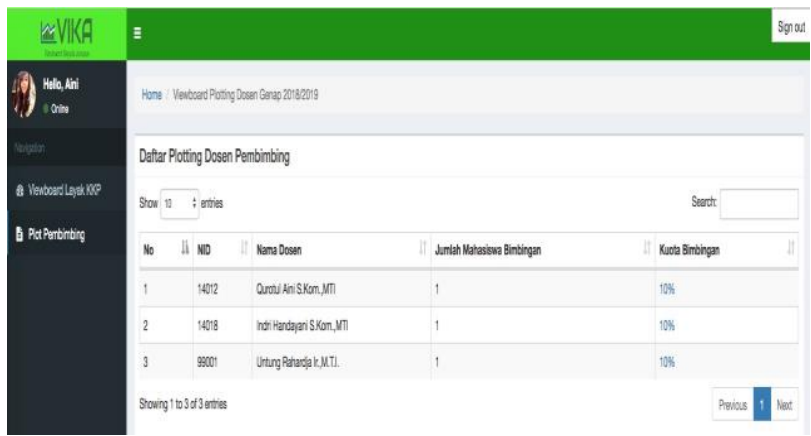

Gambar 5. Tampilan plot pembimbing

\section{Implementasi Tampilan Atur Pembimbing}

Pada menu ini adalah tampilan user untuk mengatur nama pembimbing yaitu setelah VIKA memfilter nama mahasiswa yang layak KKP, maka user akan memilih dosen pembimbing untuk setiap mahasiswa layak KKP.

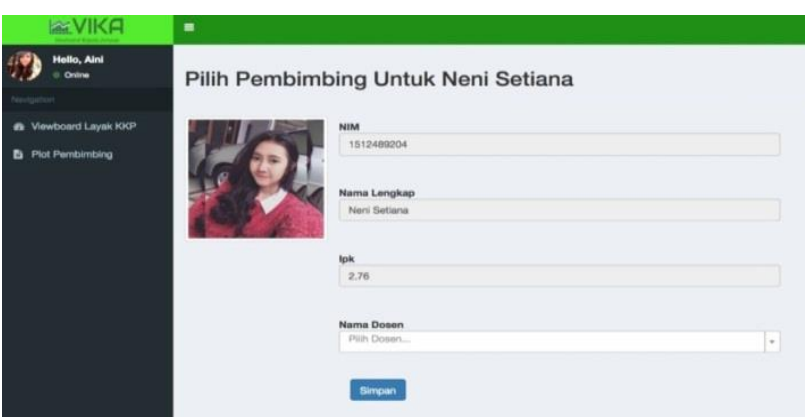

Gambar 6. Tampilan untuk mengatur pembimbing

\section{Hasil Uji Coba}

Pada tabel dibawah ini menerangkan hasil validasi mahasiswa yang dinyatakan layak KKP dan mendapat dosen pembimbing. 
Tabel 1. Hasil Validasi Perjurusan

\begin{tabular}{llcl}
\hline NIM & Nama & Pembimbing & Hasil \\
\hline 1512245456 & Nuke Puji & Erick Febriyanto Layak \\
1767436744 & Restu Adi & - & Tidak Layak \\
1675632422 & Yuliani & - & Tidak Layak \\
1614491442 & Darwin John & Qurotul Aini & Layak \\
1524434666 & Ermawanti & Indri Handayani & Layak \\
\hline
\end{tabular}

\section{Kesimpulan}

Dalam Penerapan Sistem Pengecekan Mahasiswa Layak KKP Berbasis YII Framework Pada Perguruan Tinggi maka dapat ditarik kesimpulan bahwa pengecekan mahasiswa layak KKP oleh kepala jurusan akan bersifat online, dan bisa diakses kapan dan dimana saja jika ingin melakukan assign pembimbing.

Mahasiswa secara maksimal mendapatkan pemberitahuan bahwa dirinya telah layak KKP melalui notifikasi melalui email bahwa dirinya layak KKP dan dapat diketahui saat batal tambah OJRS+.

Dengan adanya sistem VIKA (Viewboard Kepala Jurusan) sistem dapat otomatis update data mahasiswa tanpa harus bergantung kepada admin karena sistem sudah terintegrasi dengan database online.

Untuk meningkatkan sistem tersebut penulis memberikan beberapa saran yang dapat dijadikan sebagai bahan acuan dalam meningkatkan dan memajukan sistem VIKA, penulis dapat menambahkan menu untuk memilih dosen pembimbing, sistem ini dapat dikembangkan dengan berbagai fitur-fitur yang baru agar penelitian berikutnya bisa mengembangkan sistem ini lebih baik lagi, sehingga kekurangan yang ada bisa dilengkapi atau diperbaiki kedepannya.

\section{Daftar Pustaka}

[1] Kuliah Kerja Praktek (KKP) (diakses pada 20 Januari 2019) "Widuri" tersedia di https://widuri.raharja.info/index.php/Kuliah_Ke rja_Praktek_(KKP)

[2] Purwati, N., \& Kurniawan, H. (2015). Studi Pengembangan Prototype Knowledge Management Pada Pengecekan Judul Tugas Akhir atau Skripsi Fakultas Ilmu Komputer IBI Darmajaya. Proceedings Konferensi Nasional Sistem dan Informatika (KNS\&I).

[3] Kristinna, Juita. 2015. “ Analisa Sistem Validasi KKP/TA/Skirpsi Pada Sistem Sis+ Di Perguruan Tinggi Raharja”. Laporan KKP. Perguruan Tinggi Raharja.

[4] Apriyani, Ninu. 2014. "Analisa Sistem OJRS+ Sebagai Media Perencanaan Kuliah Pada Perguruan Tinggi Raharja”. KKP STMIK Raharja : Tangerang.

[5] Mude, Anastasia. 2009. "Analisa Sistem Informasi Penilaian KKP/TA/SKRIPSI Berbasis Web Pada Perguruan Tinggi Raharja". Laporan KKP. Perguruan Tinggi Raharja.

[6] Warsito, A. B., Yusup, M., \& Makaram, I. (2015). Perancangan SIS+ Menggunakan Metode YII Framework Pada Perguruan Tinggi Raharja. CCIT Journal, 8.

[7] Sugiarti, Y. (2013). Analisis \& Perancangan UML (Unified Modeling Language) Generated VB. 6. Y. Sugiarti, Analisis \& Perancangan UML (Unified Modeling Language) Generated $V B, 6$.

[8] Yuni, S. (2013). Analisis dan Perancangan UML [Unified Modelling Language] Geneerated VB. 6. Graha Ilmu Yogjakarta.

[9] Warsito, A. B., \& Yusup, M. (2014). Kajian Yii Framework dalam Pengembangan Website Perguruan Tinggi. CCIT Journal 3 (STMIK RAHARJA), 7(3), 437-451.

[10] Aini, Q., Graha, Y. I., \& Zuliana, S. R. (2017). Penerapan Absensi QRCode Mahasiswa Bimbingan Belajar pada Website berbasis YII Framework. SISFOTENIKA, 7(2), 207-218. 